\title{
Removal of Rhodamine B and Congo Red from Aqueous Solutions by Adsorption onto Activated Carbons
}

\author{
A. PAULRAJ* and A. TONY ELIZABETH
}

Post Graduate and Research Department of Chemistry, St. Joseph's College (Autonomous) Tiruchirappalli-620 002. Tamil Nadu, India

paulrajsjc@gmail.com

Received 11 October 2015 / Accepted 28 October 2015

\begin{abstract}
The present study aims at the utilization of wood based activated carbons for the effective removal of rhodamine B and congo red dyes from water. Freundlich, langmuir and Redlich-Peterson isotherm equations were applied to the equilibrium adsorption studies and the isotherm parameters were evaluated. The adsorptions were almost over within 360 minutes and the pseudo-second order rate model fits the experimental data well. $\mathrm{pH}$ of the dye solutions affect the adsorptions significantly and maximum adsorptions were found at low $\mathrm{pH}$ values. Dilute acetic acid is found to desorb much of the adsorbed dye molecules.
\end{abstract}

Keywords: Rhodamine B, Congo red, Adsorption, Adsorption isotherm

\section{Introduction}

Waters in Asian countries are most severely polluted by organic pollutants which are mainly due to the discharge of sewage and wastewaters from food, paper and pulp industries and also from textile industries ${ }^{1}$. The presence of colored organic matter in water bodies prevents the penetration of sunlight and thereby decreases the survival of aquatic organisms. In addition, the organic compounds when they degrade consume oxygen from water and increase the biological oxygen demand ${ }^{1}$. The color due to synthetic organics is also displeasing in any form of water. Dyes are colored organic compounds which are not only used for dyeing but also as colorants in all forms of materials to impart better appearance of the product. There are more than fifteen types of industrial dyes that are mainly used for dyeing purposes which includes acidic dyes, basic dyes, vat dyes, reactive dyes, direct dyes, disperse dyes and others. The production of dyes in the year as early as 1990 is estimated to be $1 \times 10^{6}$ tonnes $^{2}$. Most of the dyes used as coloring materials are toxic to aquatic organisms and some are skin-sensitive, mutagenic and carcinogenic to humans $\mathrm{s}^{2,3}$. Contamination of water resources with dyes, mainly in the surrounding areas of dyeing and textile industries, has caused great concern among environmentalists ${ }^{4}$. 
Basically, physical (adsorption, ion-exchange, coagulation-flocculation, photocatalytic degradation), chemical (oxidation and advanced oxidation processes, electrochemical processes) and biological treatment methods (aerobic and anaerobic treatments, degradation by bacteria, fungi and yeast) are available for the removal of dyes from water ${ }^{5-7}$. Of all these techniques adsorption appears to be the most suitable and economic. Many naturally available solids ${ }^{8}$, agricultural ${ }^{9-11}$ and other lignocellulosic ${ }^{12}$ and wood wastes ${ }^{13}$ as such or after conversion to activated carbon have been successfully used for the removal of dyes. Many investigators have improved the performance of these activated carbons by wet chemical treatments ${ }^{14-16}$.

The present study aims at the removal of a cationic dye (rhodamine B) and an anionic dye (congo red) from aqueous solutions using carbons prepared from waste wood shavings ${ }^{17}$. Rhodamine B (RB) is a xanthene dye which is used largely in cotton, silk and paper industries ${ }^{18}$ and can cause irritation to skin, eyes, respiratory tract and gastrointestinal tract $^{19}$. It is found to be toxic to mouse ${ }^{20}$ and housefly ${ }^{21}$. Congo red (CR) is an azo dye and is commonly used in silk clothing manufacture ${ }^{21}$. Its degradability in aqueous systems is less and is known to metabolize to benzidine, which is a known human carcinogen and the dye itself can cause an allergic reaction on humans ${ }^{22}$. The structures of RB and CR are given in Figure 1.<smiles>CCN(CC)c1ccc2c(-c3ccccc3C(=O)O)c3ccc(=[N+](Cl)CC)cc-3oc2c1</smiles>

Rhodamine B (RB)

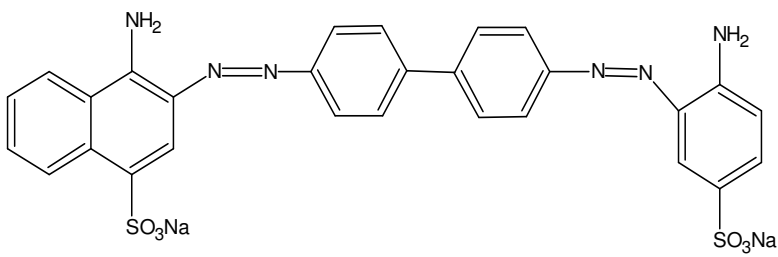

Congo Red (CR)

\section{Experimental}

Figure 1. Structures of RB and CR

Four activated carbon adsorbents were used in this study, namely $\mathrm{C} 1, \mathrm{C} 2, \mathrm{C} 3$ and $\mathrm{C} 4 . \mathrm{C} 1$ is a carbon prepared from carbonization of waste wood shavings and C2, C3 and C4 are prepared from $\mathrm{C} 1$ by wet oxidations with concentrated nitric acid, hydrogen peroxide and potassium persulphate, respectively. The methods of their preparation and characterization can be found elsewhere ${ }^{17}$.

\section{Analysis of dyes}

The concentrations of the dyes were determined by monitoring their absorptions in the visible range (at $555 \mathrm{~nm}$ for RB and $499 \mathrm{~nm}$ for CR) using a UV-Vis spectrophotometer (3000+, Lab India Analytical Instruments). Calibration graphs prepared for the concentration range $1-10 \mathrm{mg} / \mathrm{L}$ were used.

\section{Procedure for batch adsorption experiments}

All the adsorption experiments were done in batch mode at room temperature. Briefly, $50 \mathrm{~mL}$ of dye solutions were equilibrated with chosen adsorbent amounts in a mechanical shaker, filtered through Whatmann No. 41 filter paper and the filtrates were analyzed for 
remaining dye concentrations. Concentrations of dyes are varied in isotherm studies; contact time in kinetic studies and $\mathrm{pH}$ of the dye solutions (adjusted with dilute $\mathrm{HCl}$ or $\mathrm{NaOH}$ solutions) in $\mathrm{pH}$ variation studies. The amounts adsorbed at equilibrium and at time $t$ are calculated using the following equations:

$$
q_{e}=\frac{\left(C_{i}-C_{e}\right) V}{w} \quad q_{t}=\frac{\left(C_{i}-C_{t}\right) V}{w}
$$

Where, $C_{i}, C_{e}$ and $C_{t}$ are amounts of dyes at initial, equilibrium and at time $t(\mathrm{mg} / \mathrm{L}), V$ is the volume of solution (L), W is the amount of adsorbent $(\mathrm{mg})$ and $q_{e}$ and $q_{t}$ are amounts adsorbed at equilibrium and at time $t(\mathrm{mg} / \mathrm{g})$. Desorption experiments were performed as follows: after dye loading in adsorption experiments, the carbons were carefully filtered, airdried and equilibrated with $50 \mathrm{~mL}$ of the desired desorbing medium. Dilute $\mathrm{HCl}$, dilute acetic acid and water were used as the desorbing media.

\section{Results and Discussion}

\section{Properties of the adsorbents}

The physical and chemical characteristics of the carbons were reported already ${ }^{17}$ and a brief summary is presented in Table 1.

Table 1. Some physical and chemical properties of activated carbons

\begin{tabular}{lcccc}
\hline \multicolumn{1}{c}{ Property } & $\mathrm{C} 1$ & $\mathrm{C} 2$ & $\mathrm{C} 3$ & $\mathrm{C} 4$ \\
\hline BET surface area, $\mathrm{m}^{2} / \mathrm{g}$ & 544.05 & 548.10 & 586.65 & 856.98 \\
$t$-Plot Micropore area, $\mathrm{m}^{2} / \mathrm{g}$ & 490.47 & 472.91 & 503.46 & 713.26 \\
$t$-Plot External Surface Area, $\mathrm{m}^{2} / \mathrm{g}$ & 53.58 & 75.19 & 83.19 & 143.72 \\
Surface acidic groups, mequiv/g & 0.423 & 2.394 & 1.884 & 1.117 \\
Surface basic groups, mequiv/g & 0.682 & 0.158 & 0.177 & 0.424 \\
Cation exchange capacity, $\times 10^{-4} \mathrm{~mol} / \mathrm{g}$ & 1.75 & 5.50 & 4.75 & 4.50 \\
$\mathrm{pH}_{\text {ZPC }}$ & 8.57 & 4.21 & 4.51 & 5.02 \\
\hline
\end{tabular}

\section{Isotherm analysis}

The equilibrium adsorption isotherms obtained for RB and CR given in Figures 2 and 3 and three isotherm equations reported in the literature ${ }^{22}$, Freundlich, Langmuir and RedlichPeterson are used to fit these experimental data in the following forms:

Freundlich $q_{e}=K_{F} C_{e}{ }^{(1 / n)}$

Langmuir $q_{e}=\frac{K_{L} C_{e}}{\left(1+b C_{e}\right)}=\frac{q_{m} b C_{e}}{1+b C_{e}}$

Redlich - Peterson $q_{e}=\frac{K_{R} C_{e}}{\left(1+b_{R} C_{e}{ }^{\beta}\right)}$

Where, $K_{F}$ and $n$ are Freundlich constants; $K_{L}$ and $b$ are Langmuir constants; $q_{m}$ is the Langmuir monolayer adsorption capacity; $K_{R}, b_{R}$ and $\beta$ are Redlich-Peterson constants.

Each experimental data is fitted with these equations separately and the results are summarized in Tables 2 and 3. The correlation coefficient values obtained indicate that of the three models used, the three-parameter Redlich-Peterson isotherm is the best. 


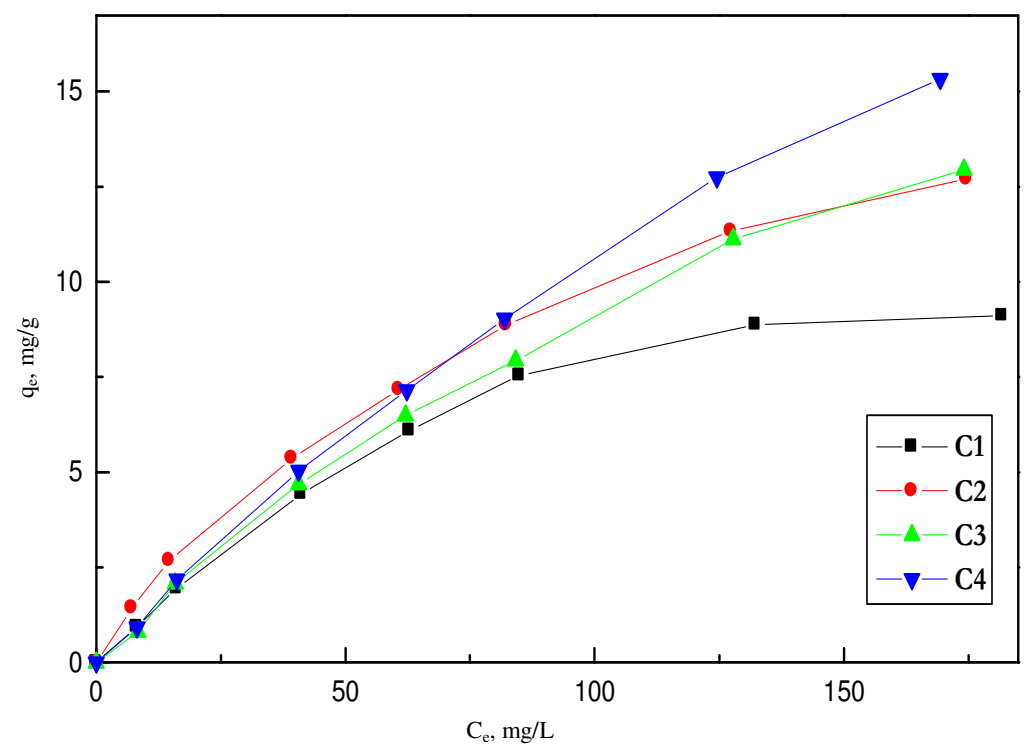

Figure 2. Adsorption isotherms of RB on activated carbons

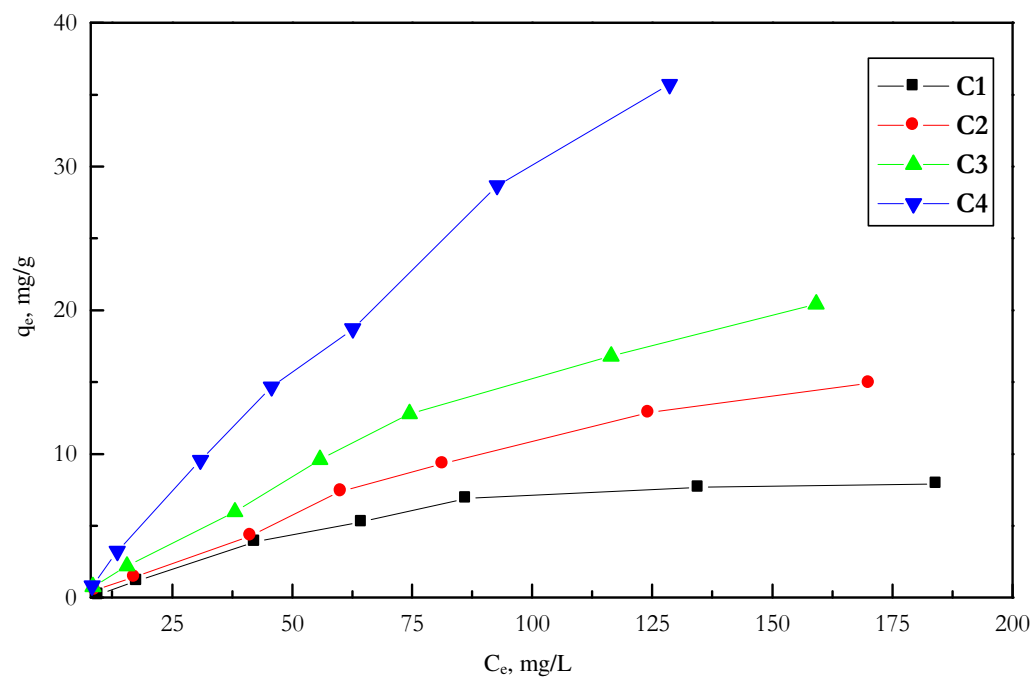

Figure 3. Adsorption isotherms of $\mathrm{CR}$ on activated carbons

The Freundlich constant $K_{F}$ is a measure of adsorption capacity and $1 / n$ is a measure of surface heterogeneity of the adsorbent. The Langmuir monolayer capacity values $\left(q_{m}\right)$ indicate that the adsorption capacities of the carbons towards both dyes increase in the order $\mathrm{C} 1<\mathrm{C} 2<\mathrm{C} 3<\mathrm{C} 4$. This is expected because the surface areas of the carbons increase in the same order. It is evident from Figure 2 that at lower concentrations of RB, C2 showed higher affinity due to the greater amounts of surface acidic groups but at higher concentrations the surface areas of the carbons decide the overall capacity and the high surface area carbons C3 and C4 displayed greater capacity. When the $q_{m}$ values for the two dyes are compared (Tables 2 and 3), C1 alone appear to have lesser capacity towards the 
retention anionic $\mathrm{CR}$ than $\mathrm{RB}$ but all other carbons have greater capacities for $\mathrm{CR}$. This may be in part due to the structural feature of $\mathrm{CR}$, being relatively lean compared to that of bulky structured RB. Entry into the pores is easier for CR than RB.

Table 2. Isotherm parameters for the adsorption of RB

\begin{tabular}{cccccc}
\hline \multirow{2}{*}{ Isotherm } & \multirow{2}{*}{ Carbon } & \multicolumn{4}{c}{ Isotherm parameters } \\
\cline { 3 - 6 } & & $K_{F}$ & $n$ & $1 / n$ & $r^{2}$ \\
\hline \multirow{4}{*}{ Freundlich } & $\mathrm{C} 1$ & 0.5605 & 1.8016 & 0.5551 & 0.9725 \\
& $\mathrm{C} 2$ & 0.5981 & 1.6584 & 0.6030 & 0.9953 \\
& $\mathrm{C} 3$ & 0.3021 & 1.6309 & 0.6132 & 0.9962 \\
& $\mathrm{C} 4$ & 0.2755 & 1.2690 & 0.7880 & 0.9980 \\
& Carbon & $K_{L}$ & $b$ & $q_{m}$ & $r^{2}$ \\
Langmuir & $\mathrm{C} 1$ & 0.1680 & 0.0120 & 14.0000 & 0.9938 \\
& $\mathrm{C} 2$ & 0.1878 & 0.0090 & 20.8667 & 0.9992 \\
& $\mathrm{C} 3$ & 0.1335 & 0.0045 & 29.6667 & 0.9990 \\
& $\mathrm{C} 4$ & 0.1416 & 0.0033 & 42.9091 & 0.9996 \\
Redlich- & Carbon & $K_{R}$ & $b_{R}$ & $\beta$ & $r^{2}$ \\
Peterson & $\mathrm{C} 1$ & 0.1471 & 0.0035 & 1.2858 & 0.9969 \\
& $\mathrm{C} 2$ & 0.2111 & 0.0210 & 0.8696 & 0.9993 \\
& $\mathrm{C} 3$ & 0.2025 & 0.1081 & 0.5298 & 0.9980 \\
& $\mathrm{C} 4$ & $0.135 \mathrm{q} 0$ & 0.0011 & 1.1944 & 0.9997 \\
\hline
\end{tabular}

Table 3. Isotherm parameters for the adsorption of CR

\begin{tabular}{cccccc}
\hline \multirow{2}{*}{ Isotherm } & \multirow{2}{*}{ Carbon } & \multicolumn{4}{c}{ Isotherm parameters } \\
\cline { 3 - 6 } & & $K_{F}$ & $n$ & $1 / n$ & $r^{2}$ \\
\hline \multirow{5}{*}{ Freundlich } & $\mathrm{C} 1$ & 0.3668 & 1.6337 & 0.6121 & 0.9497 \\
& $\mathrm{C} 2$ & 0.2232 & 1.2059 & 0.8293 & 0.9884 \\
& $\mathrm{C} 3$ & 0.3327 & 1.2195 & 0.8200 & 0.9910 \\
& $\mathrm{C} 4$ & 0.3708 & 1.0556 & 0.9473 & 0.9950 \\
& & $K_{L}$ & $b$ & $q_{m}$ & $r^{2}$ \\
Langmuir & $\mathrm{C} 1$ & 0.1284 & 0.0097 & 13.2371 & 0.9774 \\
& $\mathrm{C} 2$ & 0.1355 & 0.0029 & 46.7241 & 0.9935 \\
& $\mathrm{C} 3$ & 0.1974 & 0.0032 & 61.6875 & 0.9955 \\
& $\mathrm{C} 4$ & 0.3275 & 0.0012 & 272.9167 & 0.9960 \\
Redlich- & & $K_{R}$ & $b_{R}$ & $\beta$ & $r^{2}$ \\
Peterson & $\mathrm{C} 1$ & 0.1012 & 0.0002 & 1.6823 & 0.9896 \\
& $\mathrm{C} 2$ & 0.1297 & 0.0006 & 1.2826 & 0.9945 \\
& $\mathrm{C} 3$ & 0.1936 & 0.0017 & 1.1105 & 0.9958 \\
& $\mathrm{C} 4$ & 0.3214 & 0.0001 & 1.4792 & 0.9964 \\
\hline
\end{tabular}

The Langmuir parameter, $b$ can be used to calculate the $R_{L}$ value ${ }^{23}$ which is given by the equation: $\mathrm{R}_{\mathrm{L}}=\left[1 /\left(1+\mathrm{b} \mathrm{C}_{\mathrm{i}}\right)\right]$. The $R_{L}$ values for all the systems (Table 4$)$ lie between 0 and 1 indicating that the adsorptions are favourable ${ }^{23}$.

\section{Kinetic studies}

The kinetic curves obtained for the adsorption of RB and CR are shown in Figures 4 and 5. The kinetic data were fitted using the Lagergren's pseudo-first order kinetic model in the following linear form:

$$
\log \left(q_{e(1)}-q_{t}\right)=\log q_{e(1)}-k_{l} t
$$


Table 4. $R_{L}$ values for the adsorption of dyes

\begin{tabular}{ccccccccc}
\hline \multirow{2}{*}{$\begin{array}{c}C_{i}, \\
\mathrm{mg} / \mathrm{L}\end{array}$} & \multicolumn{4}{c}{ Rhodamine B } & \multicolumn{5}{c}{ Congo red } \\
\cline { 2 - 9 }$R_{L}$ Value & \multicolumn{5}{c}{ Value } \\
\hline & $\mathrm{C} 1$ & $\mathrm{C} 2$ & $\mathrm{C} 3$ & $\mathrm{C} 4$ & $\mathrm{C} 1$ & $\mathrm{C} 2$ & $\mathrm{C} 3$ & $\mathrm{C} 4$ \\
\hline 10 & 0.3731 & 0.3475 & 0.4283 & 0.4139 & 0.4378 & 0.4246 & 0.3362 & 0.2339 \\
20 & 0.2294 & 0.2103 & 0.2725 & 0.2610 & 0.2803 & 0.2695 & 0.2021 & 0.1325 \\
50 & 0.1064 & 0.0962 & 0.1303 & 0.1238 & 0.1348 & 0.1286 & 0.0920 & 0.0576 \\
75 & 0.0735 & 0.0663 & 0.0908 & 0.0861 & 0.0941 & 0.0896 & 0.0633 & 0.0391 \\
100 & 0.0562 & 0.0506 & 0.0697 & 0.0660 & 0.0723 & 0.0687 & 0.0482 & 0.0296 \\
150 & 0.0382 & 0.0343 & 0.0476 & 0.0450 & 0.0494 & 0.0489 & 0.0323 & 0.0200 \\
200 & 0.0289 & 0.0293 & 0.0361 & 0.0341 & 0.0375 & 0.0356 & 0.0247 & 0.0150 \\
\hline
\end{tabular}

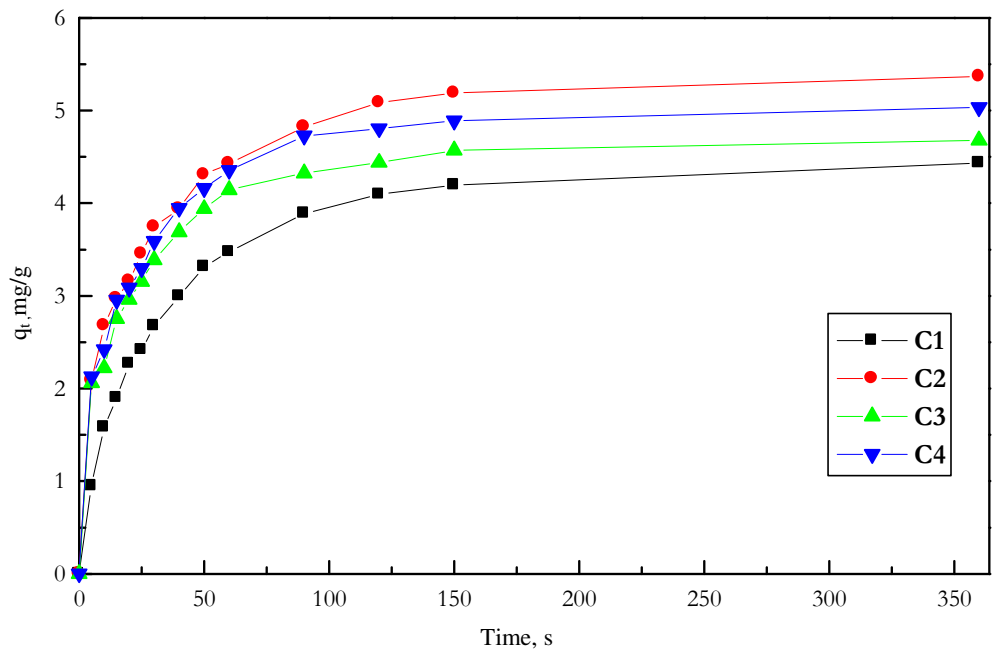

Figure 4. Kinetic curves for the adsorption of RB on activated carbons

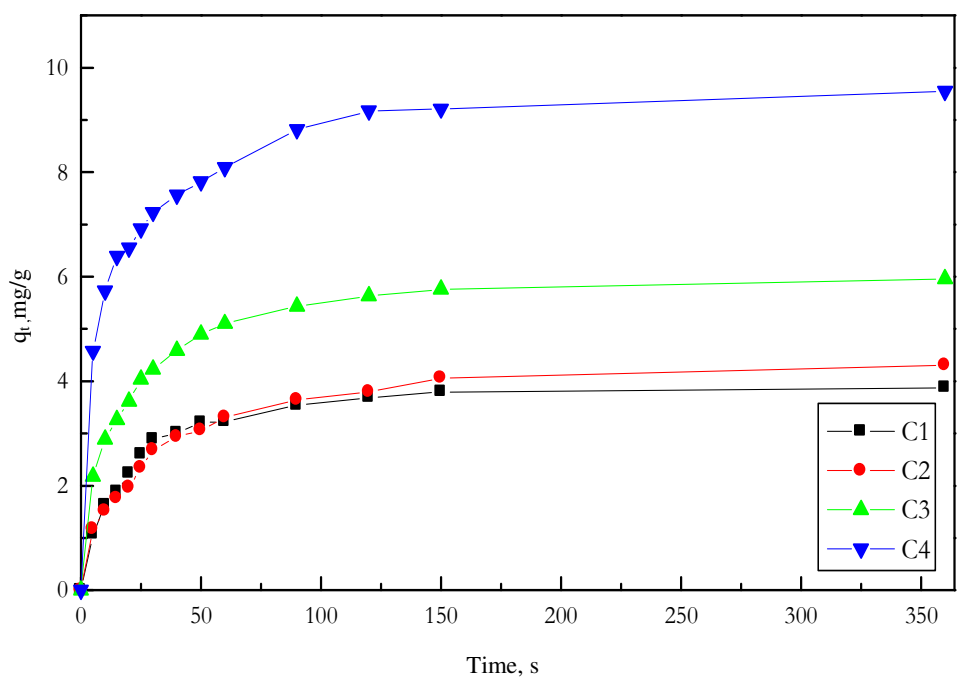

Figure 5. Kinetic curves for the adsorption of $\mathrm{CR}$ on activated carbons 
The term $k_{l}$ refers to the pseudo-first order rate constant for the sorption process $\left(\mathrm{min}^{-1}\right)$, $q_{t}$ and $q_{e(1)}$ are the amounts adsorbed at time $t$ and at equilibrium. In an analogous manner, a pseudo-second order rate model reported in the literature was also applied ${ }^{24}$. The model rate equation is given by;

$$
d q_{t}=k_{2}\left(q_{e(2)}-q_{t}\right)^{2}
$$

Where, $k_{2}$ is the overall rate constant for the sorption process $\left(\mathrm{g} \mathrm{mg}^{-1} \mathrm{~min}^{-1}\right), q_{e(2)}$ is the amount adsorbed at equilibrium $(\mathrm{mg} / \mathrm{g})$. Integration of the above equation leads to

$$
t / q_{t}=(1 / h)+\left(1 / q_{e(2)}\right) t
$$

Where $h$ is the initial sorption rate $\left(\mathrm{mgg}^{-1} \mathrm{~min}^{-1}\right)$ and is given by $h=k_{2} q_{e(2)}{ }^{2}$

The kinetic data were fitted separately to these two models and the results (Tables 5 and 6) indicate that the sorptions are better represented by the pseudo-second order model. The correlation coefficients for this model are always higher than those of the first order model with the values being greater than 0.999 all the time. It is to be noted that when $q_{e(1)}$ and $q_{e(2)}$ values of the models were compared with the experimentally observed $q_{e}$ values, once again the second order model is far better in the prediction of the adsorption capacities.

Table 5. Pseudo-first order parameters for the adsorption of dyes

\begin{tabular}{cccccc}
\hline \multirow{2}{*}{ Dye } & \multirow{2}{*}{ Carbon } & \multicolumn{2}{c}{ Equilibrium uptake, $\mathrm{mg} / \mathrm{g}$} & \multirow{2}{*}{$k_{l} \min ^{-1}$} & $\mathrm{r}^{2}$ \\
\cline { 3 - 4 } & $\mathrm{C} 1$ & $q_{e(1)}$ & $q_{\text {e(exp) }}$ & & \\
\hline \multirow{3}{*}{$\mathrm{RB}$} & $\mathrm{C} 2$ & 3.1967 & 4.4325 & 0.0080 & 0.9930 \\
& $\mathrm{C} 3$ & 2.5515 & 5.3675 & 0.0086 & 0.9972 \\
& $\mathrm{C} 4$ & 2.8275 & 5.6800 & 0.0093 & 0.9900 \\
& $\mathrm{C} 1$ & 2.5084 & 3.8750 & 0.0099 & 0.9903 \\
$\mathrm{*}$ & $\mathrm{C} 2$ & 3.0395 & 4.3058 & 0.0072 & 0.9900 \\
& $\mathrm{C} 2$ & 3.3566 & 5.9600 & 0.0086 & 0.9907 \\
& $\mathrm{C} 3$ & 4.4015 & 9.5500 & 0.0081 & 0.9865 \\
\hline
\end{tabular}

Table 6. Pseudo-second order parameters for the adsorption of dyes

\begin{tabular}{ccccccc}
\hline \multirow{2}{*}{ Dye } & Carbon & \multicolumn{2}{c}{ Equilibrium uptake, $\mathrm{mg} / \mathrm{g}$} & $\begin{array}{c}k_{2} \\
\mathrm{gmg}^{-1} \mathrm{~min}^{-1}\end{array}$ & $\begin{array}{c}h \\
\mathrm{mgg}^{-1} \mathrm{~min}^{-1}\end{array}$ & $\mathrm{r}^{2}$ \\
\cline { 3 - 6 } & $\mathrm{q} 1$ & 4.7170 & 4.4325 & 0.0100 & 0.2229 & 0.9998 \\
$\mathrm{~F} B$ & $\mathrm{q} 2$ & 5.5741 & 5.3675 & 0.0133 & 0.4146 & 0.9997 \\
& $\mathrm{C} 2$ & 4.8356 & 4.6800 & 0.0186 & 0.4348 & 0.9998 \\
& $\mathrm{C} 3$ & 5.2110 & 5.0325 & 0.0165 & 0.4473 & 0.9998 \\
\hline \multirow{4}{*}{$\mathrm{C} 4$} & $\mathrm{C} 1$ & 4.0519 & 3.8750 & 0.0176 & 0.2887 & 0.9998 \\
& $\mathrm{C} 2$ & 4.5683 & 4.3058 & 0.0099 & 0.2062 & 0.9995 \\
& $\mathrm{C} 3$ & 6.1767 & 5.9600 & 0.0130 & 0.4941 & 0.9999 \\
& $\mathrm{C} 4$ & 9.7943 & 9.5500 & 0.0106 & 1.0156 & 0.9998 \\
\hline
\end{tabular}

\section{Effect of $p H$}

$\mathrm{pH}$ had significant effect on the adsorption of both the dyes and the results are presented in Figures 6 and 7. Increasing pHs led to decrease in the adsorptions of both RB and CR. RB is a cationic dye with a carboxyl group. It is suggested that in aqueous solutions at pHs greater than 4 carboxyl group ionize and the zwitter ionic forms produced dimerize and aggregate ${ }^{25}$. On the other hand at these higher pHs the carbons' surfaces also become more negative and the RB molecules are therefore repelled. The aggregation also prevents the entry of the 
molecules into the pores. These two factors combine and the result is reduced adsorptions at high $\mathrm{pH}$ values. $\mathrm{CR}$ is an anionic dye with two sulphonate groups which ionize in water. The extent of ionization increases with increase in solution $\mathrm{pH}$ as with the surface charge of the carbons and therefore adsorptions of $\mathrm{CR}$ also decrease with increase in $\mathrm{pH}$.

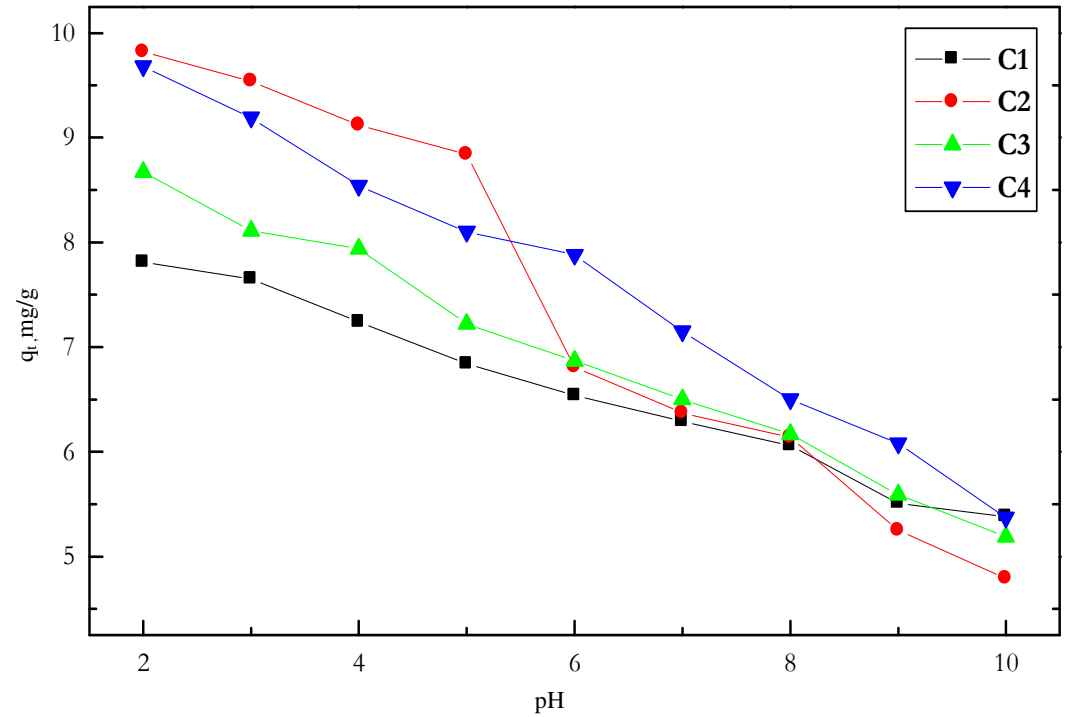

Figure 6. Effect of $\mathrm{pH}$ on the adsorption of $\mathrm{RB}$

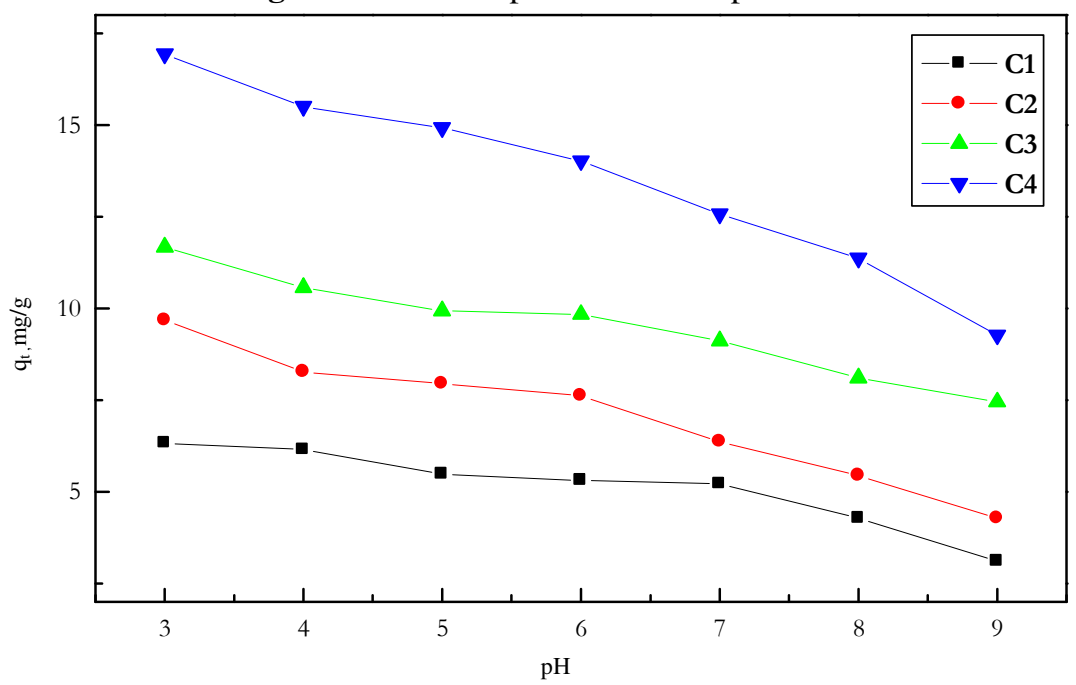

Figure 7. Effect of $\mathrm{pH}$ on the adsorption of $\mathrm{CR}$

\section{Desorption studies}

Some desorption experiments of the adsorbed dyes were done with water, dilute acetic acid and dilute hydrochloric acid. The assumptions made are that physisorption play a major role if desorption is maximum with water; chemisorption is responsible for the retention if a weak acid like acetic acid desorbs more and ion-exchange and strong electrostatic forces are 
operating when a strong acid like hydrochloric acid desorbs more. The results obtained (Table 7) indicate that desorptions are greatest with dilute acetic acid and therefore it could be concluded that chemisorptions are playing a major role in the retention of both RB and $\mathrm{CR}$ on the carbons with minor contributions from ion-exchange and physisorption.

Table 7. Results of desorption studies

\begin{tabular}{ccccccccc}
\hline Desorbing & \multicolumn{3}{c}{ \% Desorption of RB } & \multicolumn{4}{c}{ \% Desorption of CR } \\
\cline { 2 - 9 } Medium & $\mathrm{C} 1$ & $\mathrm{C} 2$ & $\mathrm{C} 3$ & $\mathrm{C} 4$ & $\mathrm{C} 1$ & $\mathrm{C} 2$ & $\mathrm{C} 3$ & $\mathrm{C} 4$ \\
\hline Water & 5.68 & 6.28 & 6.22 & 6.81 & 7.15 & 6.58 & 6.11 & 6.37 \\
Dil. AcOH & 50.08 & 65.87 & 52.61 & 51.28 & 55.38 & 69.20 & 71.19 & 68.64 \\
Dil. HCl & 11.63 & 24.58 & 22.54 & 19.67 & 12.55 & 13.22 & 12.48 & 11.85 \\
\hline
\end{tabular}

\section{Conclusion}

Activated carbons prepared from waste wood shavings were tested for their ability to remove $\mathrm{RB}$ and $\mathrm{CR}$ from aqueous solutions. The equilibrium adsorption studies indicate that the data are better represented by the three-parameter Redlich-Peterson isotherm. Langmuir monolayer adsorption capacity values for the dyes are found to maximum with the carbon of greatest surface area. Kinetic studies indicate that the sorption processes are more accurately represented by the pseudo-second order kinetic model. Increasing the $\mathrm{pH}$ of the dye solutions led to decrease in the adsorption of both RB and CR. Finally, desorption studies reveal that the dyes are adsorbed primarily by chemisorptions with little contributions from ion-exchange and physisorption.

\section{References}

1. Vladimir N Bashkin, Environmental Chemistry: Asian Lessons; Kluwer Academic Publishers; New York, 2003.

2. Klaus Hunger, Industrial Dyes Chemistry, Properties, Applications; Wiley-VCH, Verlag GmbH \&Co; KGaA, Weinheim, 2003.

3. Mittal A K and Venkobachar C, Indian J Environ Health, 1989, 31(2), 105-111.

4. $\quad$ Rita Kant, Nat Sci., 2012, 4(1), 22-26; DOI:10.4236/ns.2012.41004

5. Kamaljit Singh and Sucharita Arora, Crit Rev Env Sci Tec., 2011, 41(9), 807-878; DOI:10.1080/10643380903218376

6. Esther Forgacs, Tibor Cserhati and Gyula Oros, Environ Int., 2004, 30(7), 953-971; DOI:10.1016/j.envint.2004.02.001

7. Sanjay K Sharma, (Ed), Green Chemistry for Dyes Removal from Wastewater; Scrivener Publishing LLC; Beverly MA, 2015.

8. Pankaj Sharma, Harleen Kaur, Monika Sharma and Vishal Sahore, Environ Monit Assess., 2011, 183(1), 151-195; DOI:10.1007/s10661-011-1914-0

9. Ioannidou O and Zabaniotou A, Renew Sust Energ Rev., 2007, 11(9), 1966-2005; DOI:10.1016/j.rser.2006.03.013

10. Anastopoulos I and Kyzas G Z, J Mol Liq., 2014, 200B, 381-389; DOI:10.1016/j.molliq.2014.11.006

11. Demirbas A, J Hazard Mater., 2009, 167(1-3), 1-9; DOI:10.1016/j.jhazmat.2008.12.114

12. Norhusna Mohamad Nor, Lau Lee Chung, Lee Keat Teong and Abdul Rahman Mohamed, J Environ Chem Eng., 2013, 1(4), 658-666; DOI:10.1016/j.jece.2013.09.017

13. Dias J M, Alvim-Ferraz M C M, Almeida M F, Rivera-Utrilla J and Sanchez-Polo M, J Environ Manage., 2007, 85(4), 833-846; DOI:10.1016/j.jenvman.2007.07.031 
14. Bandosz T J, Jagiello J and Schwarz J A, Langmuir., 1996, 12(26), 6480-6486; DOI:10.1021/la960340r

15. Bagreev A, Adib F and Bandosz, J Colloid Interf Sci., 1999, 219(2), 327-332; DOI:10.1006/jcis.1999.6485

16. Jagiello J, Bandosz $\mathrm{T} \mathrm{J}$ and Schwarz J A, Carbon, 1992, 30(1), 63-69; DOI:10.1016/0008-6223(92)90107-8

17. Paulraj A and Tony Elizabeth A, Chem Sci Trans., 2015, 4(4), 1107-1115; DOI: 10.7598/cst2015.1130

18. Lata H, Mor S, Garg V K and Gupta R K, J Hazard Mater., 2008, 153(1-2), 213-220; DOI:10.1016/j.jhazmat.2007.08.039

19. Low L W, Teng T T, Alkarkhi A F M, Morad N and Azahari B, Sep Sci Technol., 2014, 49(7), 1104-1118; DOI:10.1080/01496395.2013.872148

20. Muhammed Imran Din, Zaib Hussain, Muhhamad Latif Mirza, Muhammad Makshoof Athar, Asadullah Madni and Seed Ahmad, Desalination Water Treat., 2013, 51(28-30), 5638-5648; DOI:10.1080/19443994.2013.770268

21. Bhattacharyya K G and Arunima Sharma, J Environ Manage., 2001, 71(3), 217-229; DOI:10.1016/j.jenvman.2004.03.002

22. Tsai W T, Hsu H C, Ting-Yi Su, Keng Yu Lin and Chien Ming Lin, J Colloid Interf Sci., 2006, 299(2), 513-519; DOI:10.1016/j.jcis.2006.02.034

23. McKay G, Otterburn M S and Sweeny A G, Water Res., 1980, 14(1), 21-27; DOI:10.1016/0043-1354(80)90038-X

24. Ho Y S, Adsorption., 2001, 7(2), 139-147; DOI:10.1023/A:1011652224816

25. Gad H M H and El-sayed A A, J Hazard Mater., 2009, 168(2-3), 1070-1081; DOI:10.1016/j.jhazmat.2009.02.155 